\title{
Appointment backlog could last a year or more
}

Four in ten (39\%) dental surgeons from the Faculty of Dental Surgery (FDS) at the Royal College of Surgeons of England (RCS England) predict it will take at least a year to clear the backlog of patients waiting for dental care, in the wake of COVID-19.

Nearly a third (29\%) of respondents in a survey of over 300 dental surgeons said it had been more difficult to recruit dental staff during the pandemic.

The COVID-19 pandemic has caused enormous disruption to dentistry and continues to have major implications, due to the ongoing need for enhanced infection prevention. On 25 August, the FDS published a new report, 'A resumption of dental services - one year on', based on a survey of dental surgeons that explores how services are faring now. ${ }^{1}$

The FDS says the governments of all four UK nations should prioritise tackling long waits for dental surgery alongside other types of elective surgery and recommend a particular focus on the needs of dental patients who are children or vulnerable adults.

Mr Matthew Garrett, Dean of the FDS at RCS England, said: 'The good news is that, for the most part, dental services are back up and running. Eight in ten of our members told us they were back providing routine procedures, and the majority are providing emergency treatment. That said, the pandemic created a significant backlog of patients needing treatment, which will not be cleared anytime soon. Also worrying is that up to a quarter (25\%) of our members have told us most patients on their waiting lists are children.

'Particular efforts must be made to ensure timely access to dental treatment for children and vulnerable adults, including those with special educational needs. We are concerned for example about the waiting times these groups of patients face for general anaesthetic procedures'.

The survey reports over half (54\%) of respondents saying the requirement to leave fallow time between patients, after finishing an aerosol generating procedure, is a barrier to seeing more patients. Social distancing requirements (49\%), limited availability of surgery or theatre space (30\%), inadequate ventilation (28\%) and staff shortages (25\%) were also cited by significant numbers of respondents.

The report highlights the need to prioritise the health and wellbeing of everyone working in dentistry. Nearly a third (29\%) of survey respondents said it had been more difficult to recruit dental staff during the pandemic. It also warns that a significant proportion of dental staff are considering leaving the profession in the next few years, with one in six (18\%) respondents saying that they intended to retire in the next five years, and one in ten $(10 \%)$ planning to leave the profession during the same period even though they will not have reached retirement age.

The FDS says given the delays in accessing dental care, prevention should remain a core focus within health policy across all four UK nations. The UK government's commitments to restrict junk food advertising, extend community water fluoridation initiatives, expand the provision of supervised tooth brushing schemes in England and update the School Food Standards must be delivered in full.

\section{Reference}
1. Faculty of Dental Surgery. A resumption of dental services - one year on. August 2021. Available at: https://www.rcseng.ac.uk/-/media/fds/fds-report- a-resumption-of-dental-services--one-year-on.pdf (accessed August 2021).

\section{RCSEd granted admission to The Academy}

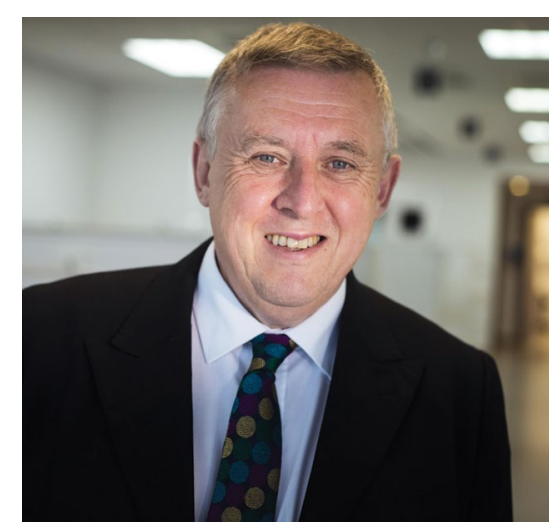

The dental faculty of one of the UK's leading surgical colleges has been granted admission to the Academy of Medical Royal Colleges (commonly referred to as The Academy).

The Royal College of Surgeons of Edinburgh's Faculty of Dental Surgery (RCSEd) has become a member of The
Academy, which will enable the Faculty and its expert members and fellows to contribute their views to collectively influence and shape healthcare across the four nations of the UK.

The Academy is the coordinating body for the UK and Ireland's 24 medical Royal Colleges and Faculties.

Professor Philip Taylor, Dean of the Faculty of Dental Surgery at the Royal College of Surgeons of Edinburgh (pictured), said: 'I am delighted the Faculty has become a member of the Academy of Medical Royal Colleges.

'We look forward to taking an active role in The Academy as we recognise their magnitude and importance in influencing and shaping healthcare for the future.

'In my manifesto when I became Dean of the Dental Faculty of RCSEd, I emphasised the importance of our role as protectors of patient safety through education and assessments, and this affiliation is another step forward in fulfilling that role.

'Joining forces with the other members of The Academy will be a fantastic opportunity for us to ensure the voice of dentistry is heard. Our Faculty acts as a place for all members of the dental profession at various stages of their career, so we feel we can truly represent the views of the entire profession'.

Professor Helen Stokes-Lampard, Chair of the Academy of Medical Royal Colleges, said: 'I am delighted to welcome Professor Taylor and his colleagues to The Academy. I look forward to their valuable input in helping us influence and improve healthcare policy across the UK for the benefit of patients across the board'. 